\title{
Inhibitory effects of PGA1 and TRI on the apoptosis of cardiac microvascular endothelial cells of rats
}

\author{
WEN-HUA PENG, JIA-LI WANG, YAN REN, YAN-XIANG GAO, GENG LI and YONG WANG \\ Department of Cardiology, China-Japan Friendship Hospital, Beijing 100029, P.R. China
}

Received April 10, 2017; Accepted July 4, 2017

DOI: $10.3892 /$ etm.2017.5079

\begin{abstract}
The present study investigated the protective effects and molecular mechanism of prostaglandin A1 (PGA1) and triptolide (TRI) on apoptosis of cardiac microvascular endothelial cells (CMVECs) in rats. CMVECs of rats were isolated and then cultured. MTT method was used to select and establish a cell hypoxia reoxygenation cell model. The cells were divided into four groups: Normoxia control group $(\mathrm{C}$, normal oxygen), hypoxia reoxygenation group (H/R, hypoxia for $12 \mathrm{~h} /$ reoxygenation for $6 \mathrm{~h}), \mathrm{PGA} 1$ group $(\mathrm{H} / \mathrm{R}+\mathrm{PGA} 1)$ and TRI group (H/R+TRI). The growth of cells in each of the group was observed. B-cell lymphoma 2 (Bcl-2) mRNA expression in CMVECs and expression of Bcl-2 mRNA after PGA1 and TRI treatment were determined by RT-PCR. Cell apoptosis was detected by terminal deoxynucleotidyl transferase-mediated dUTP nick end-labeling (TUNEL) assay. Bcl-2 mRNA decreased significantly after hypoxia stimulation of CMVECs of rats. The expression of Bcl-2 mRNA was significantly higher in comparison to hypoxia stimulation group after treatment with PGA1 and TRI $(\mathrm{P}<0.01)$. The elevated effect of PGA1 on $\mathrm{Bcl}-2$ mRNA was stronger than that of the TRI group $(\mathrm{P}<0.05)$. The number of CMVECs reduced significantly after hypoxia. By contrast, DNA fragmentation and the number of endothelial cell apoptosis were increased significantly. However, Bcl-2 mRNA expression decreased significantly, after PGA1 and TRI treatments. Furthermore, the number of apoptotic cells reduced and Bcl-2 mRNA expression increased $(\mathrm{P}<0.01)$. PGA1 and TRI significantly upregulated the expression of Bcl-2 mRNA, inhibited the activation of CMVECs and were able to achieve the protective effect on apoptosis of CMVECs in hypoxia-oxygenated rats.
\end{abstract}

\section{Introduction}

Endothelial cell apoptosis is an important mechanism of endothelial dysfunction, during heart failure. Moreover, activation of

Correspondence to: Dr Yong Wang, Department of Cardiology, China-Japan Friendship Hospital, 2 Yinghua Dongjie, Beijing 100029, P.R. China

E-mail: nuo555348zhaolai@163.com

Key words: prostaglandin A1, triptolide, Bcl-2, cardiac microvascular endothelial cell, apoptosis nerve endocrine system, inflammatory factors, oxidative factors and apoptosis factor could significantly affect the severity of heart failure $(1,2)$. Prostaglandin A1 (PGA1) and triptolide (TRI) could inhibit the extensive replication of various DNA/ RNA viruses and are related to the transcription of apoptosis factors B-cell lymphoma 2 (Bcl-2) (3-5). Upregulation of Bcl-2 expression is an improvement in cell apoptosis.

In the present study, cardiac microvascular endothelial cells (CMVECs) were isolated and cultured. After MTT test, appropriate hypoxia and oxygen time points were selected. PGA1 and TRI were then given intervention cells. Terminal deoxynucleotidyl transferase (TUNEL) along with quantitative polymerase chain reaction (qPCR) methods were used to study the effects of PGA1 and TRI on CMVECs cells, in order to reveal the molecular mechanism of endothelial cells. The present study provides a new approach for the protection of endothelial cells and the treatment of myocardial ischemia reperfusion injury.

\section{Materials and methods}

Experimental animals. Male Sprague-Dawley rats (5-7 days, weighing $200 \pm 20 \mathrm{~g}$, purchased from Beijing Vital River Laboratory Animal Technology Co., Ltd., Beijing, China) were selected, at room temperature $25 \pm 2^{\circ} \mathrm{C}$, with free access to food and water. CMVECs cells were extracted.

Main reagents. Cell culture medium, fetal bovine serum (FBS) and trypsin powder were all purchased from Gibco (New York, NY, USA). The CA Protein Quantification kit was obtained from Bi Yuntian (Shanghai, China). Rabbit anti-rat CD31 monoclonal antibody was obtained from CST (Boston, MA, USA). RNAiso Plus, PrimeScript ${ }^{\circledR}$ RT reagent kit with gDNA Eraser (Perfect Real-Time) and SYBR ${ }^{\circledR}$ Premix Ex Taq ${ }^{\mathrm{TM}}$ II (Tli RNaseH Plus) both purchased from Bao Biological (Dalian, China). In situ end-labeling assay for cell apoptosis was obtained from Roche (Basel, Switzerland). Anti Bcl-2 rabbit anti-rat monoclonal antibodies and immunofluorescence secondary antibody both from CST.

Culture of rat CMVECs. The rats were anesthetized by ether inhalation. After a further bath disinfection, the chest of rats was opened for the excision of hearts. The hearts were first placed in $4^{\circ} \mathrm{C}$ pre-cooling phosphate-buffered saline (PBS) liquid for cleaning. This was followed by cutting of the heart 
tissues into pieces. The bottom wall of the culture dish was dampened by $1 \mathrm{ml}$ FBS and the tissue block was evenly distributed in the culture dish. The culture dish was placed in an incubator at $37^{\circ} \mathrm{C}$. The culture medium $8 \mathrm{ml}$ was added to the culture dish and was cultured for $24 \mathrm{~h}$. Endothelial cell culture medium was changed after cells showed basic form. Cell culture was continued until culture grown to confluence state with $0.25 \%$ trypsin +EDTA digestion passage.

This study was approved by the Animal Ethics Committee of China-Japan Friendship Hospital Animal Center.

Identification of rat CMVECs. CMVECs specific antigen CD31 gene was used to identify CMVECs by immunofluorescence. After trypsin digestion of the primary CMVECs, the cells were placed into a $25 \mathrm{~mm}$ Petri dish with pretreated coverslip on the bottom. After 2 days, cell growth basically covered the bottom plate. After washing with PBS, formaldehyde for the fixation was used for $15 \mathrm{~min}$. BSA (5\%) was added and the incubation was performed for $30 \mathrm{~min}$ at room temperature. $\mathrm{PE}$ anti-human CD31 (dilution, 1:70; cat. no. 320806; Biolegend, Shanghai, China) was added for incubation at $4^{\circ} \mathrm{C}$ overnight with PBS washing three times. The samples were observed under fluorescence microscope (IX70; Olympus, Tokyo, Japan) after PBS cleaning.

Selection of oxygen supply time for cell hypoxia. Fused cells were randomly divided into the control group (normal oxygen), hypoxia $12 \mathrm{~h}$ /reoxygenation 3, 6 and $9 \mathrm{~h}$ group. First, the endothelial cells were placed in an anoxic culture box with a gas composition of $95 \% \mathrm{~N}_{2}+5 \% \mathrm{CO}_{2}$. After hypoxia for $12 \mathrm{~h}$, the reoxygenation MTT experiment, the optimal hypoxia and reoxygenation intervention time point (hypoxia for $12 \mathrm{~h}$ /reoxygenation for $6 \mathrm{~h}$ was the best) was selected. The growth of good primary rat CMVECs was selected, according to the results of MTT. Cells were then randomly divided into the normoxic control group ( $\mathrm{C}$, normal oxygen), hypoxia reoxygenation group (H/R, hypoxia $12 \mathrm{~h}$ /reoxygenation $6 \mathrm{~h}$ ), PGA1 group (H/R+PGA1), and TRI group (H/R+TRI).

Quantitative PCR analysis. The collected CMVECs were transferred into the $1.5 \mathrm{ml}$ reagent containing TRIzol and were placed at room temperature for $5 \mathrm{~min}$. After centrifugation at $4^{\circ} \mathrm{C}$ for $5 \mathrm{~min}$ at $12,000 \mathrm{x} \mathrm{g}$, the supernatant was carefully placed into a new Eppendorf (EP) tube. Chloroform $(0.2 \mathrm{ml})$ was added to the supernatant, mixed evenly, and placed at room temperature for $5 \mathrm{~min}$. Centrifugation was performed again for $15 \mathrm{~min}$ at $12,000 \mathrm{x} \mathrm{g}$, at $4^{\circ} \mathrm{C}$. Supernatant was absorbed into another new EP tube. The same volume of isopropanol was added after reversing several times with full mixing, and placed at room temperature for $10 \mathrm{~min}$. Centrifugation was again performed for $10 \mathrm{~min}$. The supernatant was discarded, for precipitation, $1 \mathrm{ml} \mathrm{75 \%} \mathrm{ethanol} \mathrm{was} \mathrm{added,} \mathrm{and} \mathrm{mixed}$ evenly, followed by $12,000 \mathrm{x}$ g centrifugation at $4^{\circ} \mathrm{C}$ for $5 \mathrm{~min}$. Supernatant was discarded and the process repeated. RNA concentration was then measured. The total RNA solution was diluted with RNase-free $\mathrm{H}_{2} \mathrm{O}$ into $1 \mu \mathrm{g} / \mu \mathrm{l}$, according to PrimeScript ${ }^{\circledR}$ RT reagent kit with gDNA Eraser reagent kit instructions. Prepared reverse transcription reaction liquid was added the corresponding RNA sample and the reverse transcription was performed to obtain cDNA. The cDNA was
Table I. RT-PCR primer sequences of Bcl-2 and $\beta$-actin mRNA.

\begin{tabular}{ll}
\hline Gene & \multicolumn{1}{c}{ Primer sequence $\left(5^{\prime}-3^{\prime}\right)$} \\
\hline$B c l-2$ & Forward: GAGGATTGTGGCCTTCTTTG \\
& Reverse: GTTCCACAAAGGCATCCCAG \\
$\beta$-actin & Forward: TCAGGTCATCACTATCGGCAAT \\
& Reverse: AAAGAAAGGGTGTAAAACGCA
\end{tabular}

stored at $-20^{\circ} \mathrm{C}$. According to $\mathrm{SYBR}^{\circledR}$ Premix Ex Taq ${ }^{\mathrm{TM}}$ II (Tli RNaseH Plus) reagent kit instructions, mRNA levels were determined. The corresponding RNA primer sequences are shown in Table I.

Detection of apoptosis in CMVECs. The cells with $1 \times 10^{5} / \mathrm{ml}(1.5 \mathrm{ml})$ concentration were inoculated in 24 -well plates, cultured at $37^{\circ} \mathrm{C}$ medium, for grouping model. Cells of the normoxic control group ( $\mathrm{C}$, normal oxygen), hypoxia reoxygenation group (H/R, hypoxia $12 \mathrm{~h}$ /reoxygenation $60 \mathrm{~h}$ ), PGA1 group (H/R+PGA $180 \mathrm{nmol} / \mathrm{l})$ and TRI group (H/ R+TRI $10 \mu \mathrm{g} / \mathrm{l})$ were collected, respectively. The supernatant was removed and washed with PBS (PGA1 and TRI were used for the solution with $\mathrm{Me}_{2} \mathrm{SO}$ and normal saline was diluted to a final concentration of $5 \%$, with microporous membrane for sterilization). Fixation was performed for $10 \mathrm{~min}$ with $10 \%$ paraformaldehyde in the $37^{\circ} \mathrm{C}$ incubator which was followed by washing with PBS. Permeabilization was then performed with a $0.1 \%$ Triton $\mathrm{X}-100$ in the $37^{\circ} \mathrm{C}$ incubator for $10 \mathrm{~min}$ and washed with PBS. Using 5\% skim milk for $1 \mathrm{~h}$, TUNEL detection liquid was added. Incubation was then performed at $37^{\circ} \mathrm{C}$ for $1 \mathrm{~h}$. After PBS washing, the nuclei were stained with DAPI (1:100) and observed under an inverted fluorescence microscope.

Statistical analysis. The experimental results were analyzed using SPSS 17.0 statistical software (Chicago, IL, USA). The Student's t-test, and one-way ANOVA were used for comparisons between groups. $\mathrm{P}<0.05$, was considered to indicate a statistically significant difference.

\section{Results}

Observation and identification of CMVECs. Since the third day of isolation and culture of CMVECs, under the microscope, the cells were polygonal or diamond-shaped. After replacing the cell culture medium, the cells were cultured for 4 days and the cells were fused, and then cultured for 5 days. Fully fused cells are shown in Fig. 1. Immunofluorescence CD31 staining was performed for cell identification, and a large number of CD31 positively stained cells were observed (Fig. 2), suggesting that isolated cells were endothelial cells with high purity. In this study, second generations of stably growing cells were used for intervention.

Hypoxia and reoxygenation time point by MTT method. The CMVECs cells were inoculated into a 96-well plate. After the normal adherent production of cells, the endothelial cells were placed in the anoxic culture box with a gas composition of $95 \%$ 


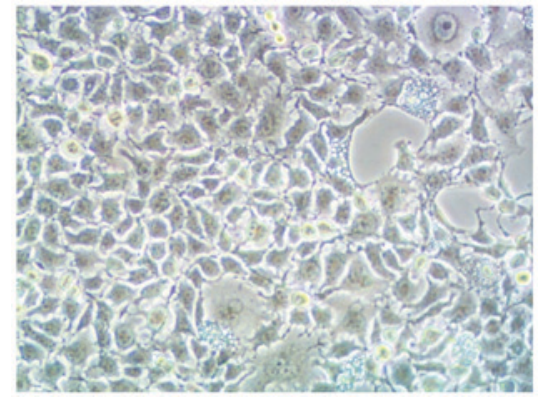

Figure 1. Morphology of cells in white light (magnification, x200). CMVECs, cardiac microvascular endothelial cells.

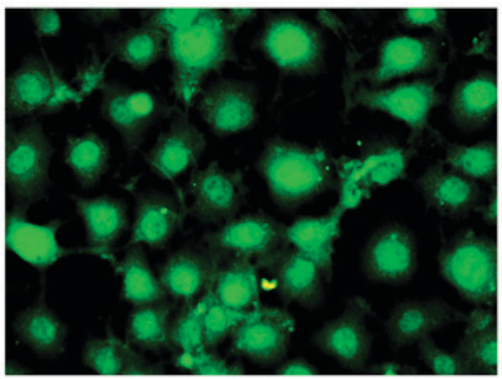

Figure 2. CD31 cell fluorescence-labeled inverted microscope of CMVECs cells (magnification, x400). CMVECs, cardiac microvascular endothelial cells.

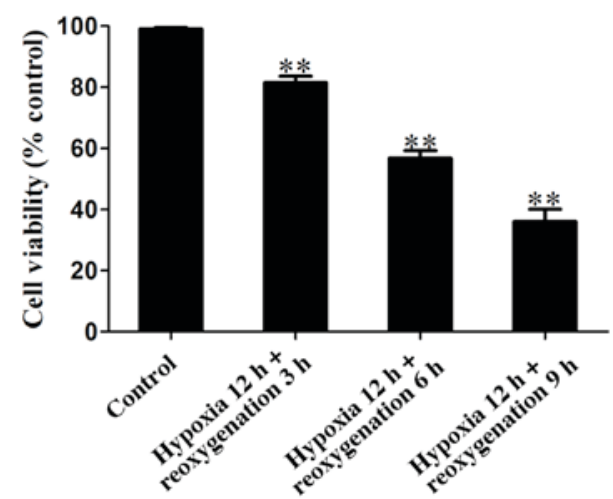

Figure 3. MTT results of CMVECs cells. Compared with the control group, ${ }^{* *} \mathrm{P}<0.01(\mathrm{n}=3)$. CMVECs, cardiac microvascular endothelial cells.

$\mathrm{N}_{2}+5 \% \mathrm{CO}_{2}$ and cultured in hypoxia for $12 \mathrm{~h}$. Hypoxia and reoxygenation experiment was performed. The groups were: control group (normal oxygen, without any stimulation), and hypoxia 12 h/reoxygenation 3, 6 and 9 h/group. Fig. 3 shows that in hypoxia for $12 \mathrm{~h} /$ reoxygenation for $3 \mathrm{~h}$, the activity of the cells was $>80 \%$, in hypoxia for $12 \mathrm{~h} /$ reoxygenation for $6 \mathrm{~h}$, cell viability decreased significantly, and the activity of cells was approximately $50 \%$, while in hypoxia $12 \mathrm{~h} /$ reoxygenation $9 \mathrm{~h}$ group, cell activity was $<30 \%$ and most of the cells died. Thus, the selection of hypoxia for $12 \mathrm{~h}$ /reoxygenation for $12 \mathrm{~h}$ was the optimal hypoxia and reoxygenation time point and the next experimental study followed.

TUNEL detection of CMVEC apoptosis ratio of different intervention groups. As shown in Fig. 4, almost no TUNEL-labeled positive cells were found in the CMVECs blank control group, suggesting that CMVECs normally had no apoptosis. Compared with the control group, a large number of TUNEL-labeled positive cells appeared in the CMVECs after hypoxia and reoxygenation, suggesting that the apoptosis rate increased significantly (Fig. 4, P<0.01). The apoptosis rates of CMVECs decreased significantly after intervention of PGA1 and TRI (Fig. 4, P<0.01). Thus, PGA1 and TRI significantly reduced cell apoptosis.

Effects of PGA1 and TRI on the expression of Bcl-2 mRNA. As shown in Fig. 5, compared with the blank control group, Bcl-2 mRNA expression of CMVECs significantly reduced after oxygen stimulation $(\mathrm{P}<0.05)$. The expression of Bcl-2 after PGA1 and TRI intervention significantly increased. Moreover, the elevated effect of PGA1 was better than that of TRI.

\section{Discussion}

In recent years, with the rapid development of cardiac surgery, myocardial ischemia reperfusion injury has been the focus of active study (6). Previous studies have shown that by the inhibition of inflammation, oxidative stress and apoptosis could significantly alleviate myocardial ischemiareperfusion injury (7). In this study, PGA1 and triptolide alcohol in vivo (TRI) significantly inhibited microvascular endothelial cell (CMVECs) apoptosis and significantly decreased the expression of Bcl-2 mRNA, to inhibit apoptosis of CMVECs. This suggested that PGA1 and TRI could improve the cell injury and play a protective role of CMVEC apoptosis in rats.

Donor heart ischemia reperfusion injury after cardiac transplantation is the process of affecting the survival of transplanted hearts. Although many factors contribute to the cause of ischemia reperfusion injury, the downregulation of
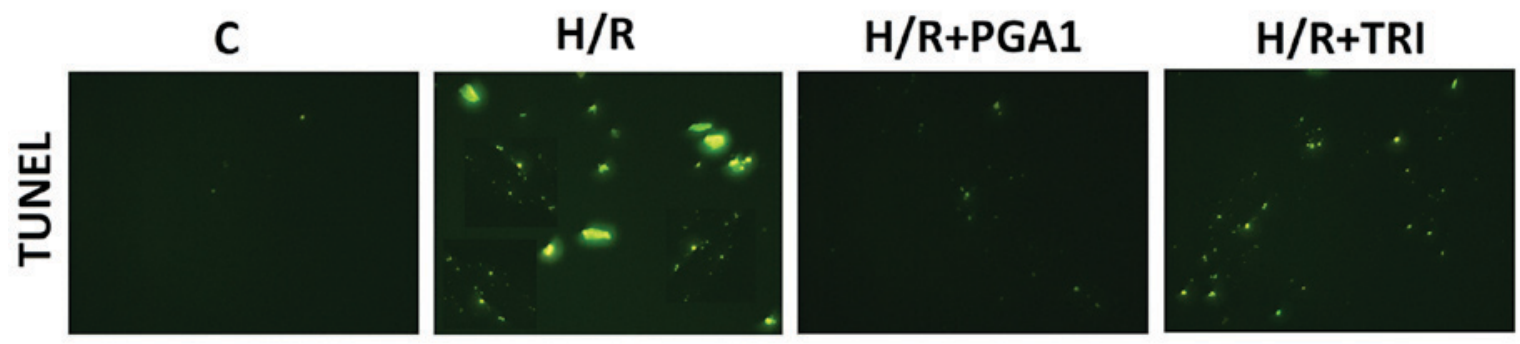

Figure 4. TUNEL results of CMVECs. TUNEL, terminal deoxynucleotidyl transferase-mediated dUTP nick-end labeling; CMVECs, cardiac microvascular endothelial cells. 


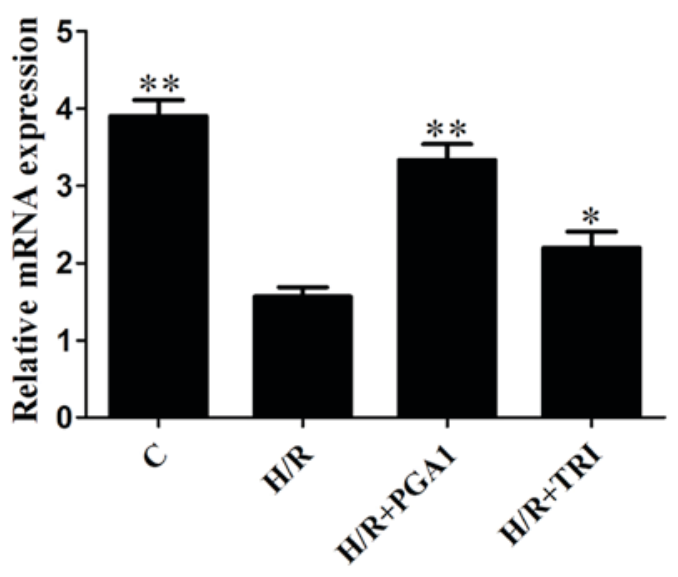

Figure 5. Effect of PGA1 and TRI on the expression of Bcl-2 mRNA. Compared with hypoxia reoxygenation model group, ${ }^{*} \mathrm{P}<0.05,{ }^{* *} \mathrm{p}<0.01$ $(\mathrm{n}=3)$. PGA1, prostaglandin A1; TRI, triptolide; Bcl-2, B-cell lymphoma 2; RT-PCR, real-time polymerase chain reaction.

the apoptosis factor and the promotion of apoptosis factor expression play an important role in reperfusion injury $(8,9)$. Previous studies have shown that in endothelial cell injury a large number of apoptotic bodies are produced and the $\mathrm{Bcl}-2$ plays a crucial role (10). Bcl-2 is an important inhibitor of apoptosis and could inhibit cell death caused by various cy totoxic factors (11). Bcl-2 not only acts on cancer cells in stage $\mathrm{G} 2 / \mathrm{M}$ and participates in apoptosis, but also significantly enhances the expression of mutant $\mathrm{p} 53$ and Bax proteins in cells (12). The value-added process of endothelial cells is determined by a series of rules of gene regulation. Apoptosis is the only way to renew cells. Apoptosis of endothelial cells after ischemia reperfusion injury may be due to the severe downregulation of anti-apoptotic factor Bcl-2 $(13,14)$. In that study through the in vitro culture of CMVEC cells PGA1 and TRI intervention therapy was administered, suggesting that PGA1 and TRI significantly improved the decreased expression of Bcl-2 mRNA induced by myocardial ischemia reperfusion. The TUNEL experimental results showed that the damage of DNA also had significant improvement. This experiment proved the importance of Bcl-2 in heart ischemia reperfusion, and laid the foundation for further mechanism research.

PGA1 is a kind of cyclization of 20 carbon fatty acids with many biological activities (15). Clinical application of PGA1 on essential hypertension, renal hypertension, diabetic hypertension and pheochromocytoma hypertension has significant antihypertensive effect. It has been reported that PGA1 had potent anti-inflammatory effects $(16,17)$. TRI is two mushroom complex compound containing epoxy isolated from Tripterygium wilfordii (18). TRI has a strong physiological activity, widely used in clinical research and research shows that it has antioxidant, anti-rheumatoid, anti-Alzheimer's disease, anticancer and other effects (19). It is reported that TRI has anti-inflammatory, anti-oxidation and inhibitory effects on apoptosis (20). However, the relationship between PGA1, TRI and ischemia reperfusion is not understood well. Through TUNEL apoptosis staining and qPCR experiments, we found that PGA1 and TRI had a strong protective effects on CMVECs cell injury induced by hypoxia reperfusion (the protective effect of PGA1 was stronger than that of TRI). These results provided a new direction of treatment to myocardial ischemia reperfusion, and confirmed that both PGA1 as well as TRI are potential drugs for the treatment of myocardial ischemia reperfusion.

In the present study, PGA1 and TRI inhibited the apoptosis of rat CMVECs by upregulation of the expression of Bcl-2 mRNA. PGA1 and TRI, not only alleviated the injury of vascular endothelial cells in hypoxia and oxygen, but also protected the function of endothelial cells. Thus, both have wide application prospects in the treatment of myocardial ischemia reperfusion injury.

\section{References}

1. Aird WC: Phenotypic heterogeneity of the endothelium: II. Representative vascular beds. Circ Res 100: 174-190, 2007.

2. Cooper DL, Carmical JA, Panus PC and Harirforoosh S: Formulation andin vitro evaluation of niacin-loaded nanoparticles to reduce prostaglandinmediated vasodilatory flushing. Eur Rev Med Pharmacol Sci 19: 3977-3988, 2015.

3. Boller YC, Brandes LM, Russell RL, Lin ZP, Patierno SR and Kennedy KA: Prostaglandin A1 inhibits stress-induced NF-kappaB activation and reverses resistance to topoisomerase II inhibitors. Oncol Res 12: 383-395, 2000.

4. Hu K, Liu Z and Liu D: Triptolide inhibits vascular endothelial growth factor expression and production by endothelial cells. Zhonghua Yi Xue Za Zhi 81: 1106-1109, 2001 (In Chinese).

5. Popovic JK, Grujic Z, Grujic I, Bogavac M, Celic D, Popovic KJ, Jakovljevic A and Popovic DJ: Prostaglandin E2, trace elements and levels of oxidative processes in spontaneous miscarriages. Eur Rev Med Pharmacol Sci 20: 4786-4790, 2016.

6. Grandmougin D, Vanhuyse F, Fiore A, Delolme MC, Liu Y, Laurent N, Bertram M, Folliguet T, Tran N and Maureira JP: Effects of the self-myocardial retroperfusion with aortic-coronary sinus shunt on cardiac output and ischemic events in high-risk patients undergoing OPCAB surgery. J Cardiovase Surg (Torino) 56: 929-937, 2015.

7. Li X, Liu M, Sun R, Zeng Y, Chen S and Zhang P: Protective approaches against myocardial ischemia reperfusion injury. Exp Ther Med 12: 3823-3829, 2016.

8. Klingel K, Rieger P, Mall G, Selinka HC, Huber M and Kandolf R: Visualization of enteroviral replication in myocardial tissue by ultrastructural in situ hybridization: Identification of target cells and cytopathic effects. Lab Invest 78: 1227-1237, 1998.

9. Youle RJ and Strasser A: The Bcl-2 protein family: Opposing activities that mediate cell death. Nat Rev Mol Cell Biol 9: 47-59, 2008.

10. Hsieh PC, Davis ME, Lisowski LK and Lee RT: Endothelialcardiomyocyte interactions in cardiac development and repair. Annu Rev Physiol 68: 51-66, 2006.

11. Huber SA, Haisch C and Lodge PA: Functional diversity in vascular endothelial cells: Role in coxsackievirus tropism. J Virol 64: 4516-4522, 1990.

12. Salakou S, Kardamakis D, Tsamandas AC, Zolota V, Apostolakis E, Tzelepi V, Papathanasopoulos P, Bonikos DS, Papapetropoulos T, Petsas T, et al: Increased Bax/Bcl-2 ratio up-regulates caspase- 3 and increases apoptosis in the thymus of patients with myasthenia gravis. In Vivo 21: 123-132, 2007.

13. Gioacchini FM, Alicandri-Ciufelli M, Rubini C, Magliulo G and $\mathrm{Re} \mathrm{M}$ : Prognostic value of $\mathrm{Bcl}-2$ expression in squamous cell carcinoma of the larynx: A systematic review. Int J Biol Markers 30: e155-e160, 2015.

14. Choi JE, Woo SM, Min KJ, Kang SH, Lee SJ and Kwon TK: Combined treatment with ABT-737 and VX-680 induces apoptosis in Bcl-2- and c-FLIP-overexpressing breast carcinoma cells. Oncol Rep 33: 1395-1401, 2015.

15. Gharbi S, Garzón B, Gayarre J, Timms J and Pérez-Sala D: Study of protein targets for covalent modification by the antitumoral and anti-inflammatory prostaglandin PGA1: Focus on vimentin. J Mass Spectrom 42: 1474-1484, 2007.

16. Gayarre J, Stamatakis K, Renedo M and Pérez-Sala D: Differential selectivity of protein modification by the cyclopentenone prostaglandins PGA1 and 15-deoxy-Delta12,14-PGJ2: Role of glutathione. FEBS Lett 579: 5803-5808, 2005. 
17. Elia G,Polla B, Rossi A and Santoro MG: Induction of ferritin and heat shock proteins by prostaglandin A1 in human monocytes. Evidence for transcriptional and post-transcriptional regulation. Eur J Biochem 264: 736-745, 1999.

18. Qiu D and Kao PN: Immunosuppressive and anti-inflammatory mechanisms of triptolide, the principal active diterpenoid from the Chinese medicinal herb Tripterygium wilfordii Hook. $\mathrm{f}$. Drugs R D 4: 1-18, 2003.
19. Liu H, Liu ZH, Chen ZH, Yang JW and Li LS: Triptolide: A potent inhibitor of NF-kappa B in T-lymphocytes. Acta Pharmacol Sin 21: 782-786, 2000

20. Jiang XH, Wong BC, Lin MC, Zhu GH, Kung HF, Jiang SH, Yang D and Lam SK: Functional p53 is required for triptolideinduced apoptosis and AP-1 and nuclear factor-kappaB activation in gastric cancer cells. Oncogene 20: 8009-8018, 2001. 